International Journal of Engineering \& Technology, 7 (2.29) (2018) 1126-1129
International Journal of Engineering \& Technology
SPC
Website: www.sciencepubco.com/index.php/IJET
Research paper

\title{
Physical Properties and Total Phenolic Content by Different Drying and Extraction Techniques of Clinacanthus Nutans Leaves
}

\author{
Yvonne Melse Laurence $^{1,2, *}$ Mohammad Shaheen Khan $^{1}$ and Mohd Sani Sarjadi ${ }^{1 *}$ \\ ${ }^{1}$ Faculty of Science and Natural Resources, Universiti Malaysia Sabah, Jalan UMS, \\ 88400 Kota Kinabalu, Sabah, Malaysia. \\ ${ }^{2}$ Knowledge and Technology Management Division, \\ Sabah Economic Development \& Investment Authority (SEDIA), \\ 88873, Kota Kinabalu, Sabah, Malaysia. \\ *Corresponding author E-mail: yvonne@sedia.com.my;
}

\begin{abstract}
This report presents a series of different drying condition and extraction methods on Clinacanthus nutans leaves. C. nutans leaves were dried using three different drying conditions: oven $\left(40^{\circ} \mathrm{C}, 60^{\circ} \mathrm{C}\right.$ and $\left.80^{\circ} \mathrm{C}\right)$, vacuum oven and air drying. Then, the physical properties of dried leaves obtained were analyzed in terms of the moisture content and water activity. Thus, the series of extraction was performed using three different extraction techniques: soxhlet, maceration and ultrasound-assisted solvent extraction respectively. Finally, the total phenolic content of each extracts were determined with the Folin-Ciocalteu method. The results showed that the choice of drying method and extraction technique influenced the phenolic compound yield of $C$. nutans extract. Excellent performance of the combination of drying $C$. nutans leaves using laboratory oven at $60^{\circ} \mathrm{C}$ and soxhlet extraction obtained the highest total phenolic content yield at $65.92 \pm$ $2.19 \mathrm{mg} \mathrm{GAE} / \mathrm{g}$.
\end{abstract}

Keywords: Clinacanthus nutans, Drying, Extraction method, Physical properties, Phenolic content

\section{Introduction}

Clinacanthus nutans (Burm. f.) Lindau is a local medicinal herb that is more commonly known among Malaysian as Sabah Snake Grass or Belalai Gajah (Lusia et al., 2015). C. nutans plant is native to many tropical Asian countries and belongs to the family of Acanthaceae (Huang et al., 2015). Due to an increase in public awareness of its potential medicinal properties, many studies were conducted to investigate the biological activities of $C$. nutans. Therefore, it is highly significant to optimize the extraction yield of these bioactive compounds. Previous studies has reported that factors such as herb dehydration, extraction solvent and techniques would have considerable effect on the phenolic compounds yield from crude extract of plants (Khoo et al., 2015; Kumar, 2013). The aim of this study was to determine the influence of different drying conditions on the physical properties of $C$. nutans leaves and to evaluate the result of combining different drying methods and extraction techniques on crude extract yield and total phenolic content (TPC) of $C$. nutans leaves.

\section{Literature Review}

C. nutans is a perennial herb widely distributed in Malaysia, Thailand and Indonesia (Arullappan et al., 2014). It is a shrub with pubescent branches that can grow 1 - 3 meter in height. The plant grows well at the elevation ranging from 500 to $620 \mathrm{~m}$, particular- ly at low altitude forest area that are scattered (Zulkipli et al., 2017). The leaves are pale green, with simple, narrowly elliptic, oblong or lanceolate-ovate shapes, that ranges between $2.5-13$ $\mathrm{cm}$ long and $0.5-1.5 \mathrm{~cm}$ wide. The plant's stems are terete, striate and glabrescent while the petioles are sulcate, bifariously pubescent and between $0.3-2 \mathrm{~cm}$ long. $C$. nutans formed flowers in compact cymes that are dull red in color with green base and yellow stripes on the lower lip (Kunsorn et al., 2013; Alam et al., 2016; Zulkipli et al., 2017).

\subsection{Medicinal Properties}

C. nutans has been used in the preparation of traditional remedies in Malaysia and other Asian countries for treating nettle rash, blisters, oral inflammatory symptoms, burns, dysentery, insect stings, gout, fever, urinates neuropathies, kidney problems, nasal cavity cancer, liver cancer and uterine fibroid (Arullappan et al., 2014; Peng et al., 2014; Zulkipli et al., 2017). A study by Pannangpetch et al. (2007) concluded that ethanolic extract of $C$. nutans exhibited free radicals scavenging activity, ferric reducing antioxidant power (FRAP) and exerted intracellular inhibition towards phorbol myristate acetate (PMA)-induced free radical production. The study by Mai et al. (2016) concluded that the most potent extract is polar leaves extracts of $C$. nutans which shows anti-inflammatory effect by the inhibition of all LPS induced TLR -4 inflammatory proteins. C. nutans extract also shows inhibitory effect towards herpes simplex virus (HSV) and vavicella- zostervirus (VSZ) (Kunsorn et al., 2013; Thawaranantha et al., 1992). C. nutans was also shown to have signif- 
icant antibacterial effect against Staphylococcus aureus and Escherichia coli in a study by Ho et al. (2013).

\subsection{Chemical Constituents}

Chemical compounds such as glycosides, glycoglycerolipids, cerebrosides, lupeol, b-sitosterol, stigmasterol, belutin, shaftoside, isoorientin, orientin, isovitexin, and vitexin, steroids, triterpenoids monoacylmonogalactosylglycerol, clinamides A, clinamides B and clinamides C, 2-cis-entadamide A, isomollupentin 7-O- $\beta$ glucopyranoside, 6,8-apigenin-C- $\alpha$-1-pyranarabinoside, pupurin18-phytyl ester, chlorophyll derivatives and phaeophorbide have already been documented from the phytochemical studies of $C$. nutans leaves extract when different solvent for extraction are used (Alam et al., 2016; Aslam et al., 2015; Huang et al., 2015; Tu et al., 2014). A study by Sakdarat et al. (2009) has isolated different types of chlorophyll A and chlorophyll B compounds from chloroform extract of $C$. nutans leaves. The chlorophyll A related compounds were $13^{2}$-hydroxy- $\left(13^{2}-\mathrm{R}\right)$-phaeophytin $\mathrm{A}$, phaeophorbide A, $13^{2}$-hydroxy-( $\left.13^{2}-\mathrm{S}\right)$-phaeophytin A and purpurin-18-phytyl ester, whereas the chlorophyll $\mathrm{B}$ related compounds isolated in the study were $13^{2}$-hydroxy- $\left(13^{2}-\mathrm{R}\right)$-chlorophyll $\mathrm{B}$, $13^{2}$-hydroxy- $\left(13^{2}-\mathrm{R}\right)$-phaeophytin B, $13^{2}$-hydroxy- $\left(13^{2}-\mathrm{S}\right)$ chlorophyll B and $13^{2}$-hydroxy-(132-S)-phaeophytin B (Sakdarat et al., 2009).

\subsection{Sample Drying}

Herb drying is the process in which the moisture content of a plant material is reduced to a safe level to obtain stable products that can be store for long period of time without deterioration. Dried herbs can be stored at $5-7^{\circ} \mathrm{C}$ for more than 12 months. The water activity of dried samples can be measured to determine whether enough water molecules were evaporated from the samples to prolong the shell life. Water activity indicates the capability of water molecules present in the samples that can take part in a chemical reaction which then leads to microbial degradation. The water activity of a dry product should not exceed the physiological water activity of $0.60 \mathrm{a}_{\mathrm{w}}$, which is responsible for microbiological deterioration (Kumar, 2013)

The study by Raya et al. (2015) demonstrated that without proper drying treatment, the phytochemical, chlorophyll and ascorbic acid content of $C$. nutans plant will progressively decrease through prolong storage. The right drying parameters need to be determined so that the plant are not subjected to excessive heat that can cause major loss of their medicinal, culinary, visual and nutraceutical properties (Puranik et al., 2012).

\subsection{Extraction of the Phenolic Compound}

Phenolic compounds are the most abundant plant secondary metabolites that possessed at least one or additional aromatic rings with one or additional hydroxyl groups attached (Fig. 1). Phenolic compounds comprised of phenolic acids, coumarins, curcuminoids, lignans, quinones, flavonoids, stilbenes and condensed tannins (Blainski et al., 2013). Generally, plant phenolic are involved in the plant's biological function such as defense mechanism against ultraviolet radiation or damages done by all types of pathogens, parasites and predators, as well as plant pigmentation which contribute to the plant's colors (Dai and Mumper, 2010).<smiles>Oc1ccccc1</smiles><smiles>Oc1ccccc1</smiles>

Fig 1: Structure of phenol which is the simplest phenolic compound; $\left(\mathrm{C}_{6} \mathrm{H}_{6} \mathrm{O}\right)$
These phenolic compounds from liquid and solid sample can be extracted using different extraction techniques. The conventional extraction technique such as soxhlet extraction, hydrodistillation and maceration combines solvent of choice with the use of heat or agitation to extract nutraceuticals from plant matrices (Wang and Weller, 2006). Conventional extraction techniques are usually time consuming, tedious and require the use of large amount of organic solvent but it is still widely used due to its simplicity. Modern extraction technique such as ultrasound assisted extraction (UAE), microwave assisted extraction (MAE), supercritical fluid extraction (SFE) and accelerated solvent extraction (ASE) shows promising potential in the extraction of bioactive compound from plants at laboratory or bench-scale (Wang and Weller, 2006). These methods have demonstrated in various studies that smaller volume of organic solvent can be use while allowing a faster extraction of organic compounds.

\section{Materials and Methodology}

\subsection{Reagents and Chemicals}

Methanol $\left(\mathrm{CH}_{3} \mathrm{OH}\right)$ used for extraction was of analytical grade and purchased from Thermo Fisher Scientific. The chemical sodium carbonate $\left(\mathrm{NaCO}_{3}\right)$ was supplied by Sigma-Aldrich, Germany while the Folin-Ciocalteu's phenol $\left(\mathrm{C}_{6} \mathrm{H}_{5} \mathrm{OH}\right)$ reagent and gallic acid $\left(\mathrm{C}_{7} \mathrm{H}_{6} \mathrm{O}_{5}\right)$ were obtained from Merck, Germany.

\subsection{Samping}

C. nutans samples were collected from the herbal nursery at the project Plot-Demo UNDP/GEF-IDS situated at Mile 30, Kimanis, Papar, Sabah, Malaysia. The plant was rinsed with tap water to remove any dirt and dried with tissue paper. The fresh leaves and stem was separated for further study.

\subsection{Preparation of Dried C. Nutans Samples}

C. nutans fresh leaves of were dried to constant weight using three different drying conditions.

Oven drying: The leaves are placed on a tray and dried in the universal oven until samples achieved constant weight at three predetermined temperature: $40^{\circ} \mathrm{C}$ (UO40), $60^{\circ} \mathrm{C}$ (UO60) and $80^{\circ} \mathrm{C}$ (UO80).

Vacuum oven drying: The leaves are placed on a tray and dried until constant weight in a vacuum oven at $60^{\circ} \mathrm{C}$ temperature with pressure of 100 mbar (VO60).

Air drying: Drying was carried out by spreading the leaves evenly on a tray, covered with tissue sheets to keep off debris and insects. The leaves are turned from time to time and left to dry in a shade place $\left(35^{\circ} \mathrm{C}\right)$ with proper air flow for 2 weeks $(A D)$.

The dried $C$. nutans leaves were ground to fine powder with an electric blender and then stored in a cold room until required.

\subsection{Sample Drying}

Extraction of dried samples was performed using three different extraction techniques which include soxhlet, maceration and ultrasound-assisted solvent extraction.

Soxhlet Extraction: Powdered plant material $(10.0 \mathrm{~g})$ is extracted with $100 \mathrm{ml}$ of $80 \%$ methanol in a soxhlet apparatus.

Maceration: The extraction is carried out using powdered plant material $(10.0 \mathrm{~g})$ in a conical flask immersed with $50 \mathrm{ml}$ of $80 \%$ methanol and placed on a mechanical shaker at room temperature with constant stirring rate at $120 \mathrm{rpm}$ for $48 \mathrm{~h}$.

Ultrasound-assisted extraction (UAE): Extraction was done in an Elmasonic S900H ultrasonic bath at a constant power of $2000 \mathrm{~W}$ and ultrasonic frequency at $37 \mathrm{kHz} .10 .0 \mathrm{~g}$ of fine $C$. nutans pow- 
der were immersed in $80 \%$ methanol at 1:5, sample to solvent ratio and subjected to sonication for $60 \mathrm{~min}$ at room temperature $\left(25 \pm 1^{\circ} \mathrm{C}\right)$.

The extracts obtained are filtered, then concentrated and evaporated using rotary evaporator and stored in a refrigerator until further analysis.

\subsection{Determination of Physical Properties}

Moisture content of dried leaves samples from different drying methods was measured using Boeco moisture analyzer BMA H50 while the water activity content was measured with the water activity meter Novasina Labtouch aw equipment.

\subsection{Determination of Total Phenolic Content (TPC)}

Total phenolic content (TPC) of extract was determined using Folin Ciocalteu assay according to the procedure described by Pham et al. (2015). Mix $0.5 \mathrm{ml}$ of extract with $2.5 \mathrm{ml}$ of $10 \%(\mathrm{v} / \mathrm{v})$ Folin-Ciocalteu reagent. After $7 \mathrm{~min}, 2 \mathrm{ml} 7.5 \%(\mathrm{w} / \mathrm{v})$ sodium carbonate was then added to the sample solution before the samples are incubated in a dark room for $1 \mathrm{~h}$ at room temperature. The absorbance value was measured at $765 \mathrm{~nm}$ using a UV-VIS spectrophotometer (Genesys 10S UV-Vis spectrophotometer). Gallic acid standard curve was prepared and results were stated as mg of gallic acid equivalent (GAE) per $g$ of dried weight. Three replicates of each sample extract were analyzed.

\section{Results and Discussion}

\subsection{Physical Properties of $C$. nutans Leaves}

The $C$. nutans leaves were dried using three different drying conditions including oven drying $\left(40^{\circ} \mathrm{C}, 60^{\circ} \mathrm{C}\right.$ and $\left.80^{\circ} \mathrm{C}\right)$, vacuum oven and air drying and the result was tabulated in Table 1. Overall data showed that different drying parameter would produce significant variation $(\mathrm{p}<0.05)$ on both moisture content and water activity of $C$. nutans. Fresh $C$. nutans leaves samples have an average moisture content of $69.19 \pm 0.38 \%$. The moisture content of dried $C$. nutans leaves obtained through different drying methods ranged from $8.41 \%$ to $12.03 \%$, of which UO80 achieved the lowest moisture content at $8.41 \%$ while the highest moisture content was from air dried samples at $12.03 \%$. It was also observed that as the temperature used for drying increased, the time duration needed for dried leaves samples to reach constant moisture content is reduced. Similar observation were obtained in a study by Solibun and Sivakumar (2016) for $C$. nutans leaves dried at different oven drying temperature. Higher temperature stimulates water molecules evaporation from leaves surface more vigorously and resulted in reduce drying duration. Drying method using lower temperatures such as UO40 and air drying retained higher moisture content and showed that the samples were unable to be dehydrated completely even when subjected to longer drying time.

The results showed that $C$. nutans leaves dried under different drying methods have water activity values that range from 0.43 to $0.56 \mathrm{a}_{\mathrm{w}}$. These values are still within the safe range that can hinder enzyme activity, bacterial and fungi growth. Water activity of a dry product not exceeding 0.6 is considered microbiological stable and could be store for extended period of time with minimum microbiological deterioration (Susantikarn and Donlao, 2016).
Table 1: Moisture content and water activity of $C$. nutans leaves data

\begin{tabular}{|c|c|c|c|}
\hline $\begin{array}{c}\text { Drying } \\
\text { Method }\end{array}$ & $\begin{array}{c}\text { Drying Time } \\
\text { (Hours) }\end{array}$ & $\begin{array}{c}\text { Moisture Con- } \\
\text { tent }(\%)\end{array}$ & $\begin{array}{c}\text { Water } \\
\text { Activity } \\
\left(\mathrm{a}_{\mathrm{w}}\right)\end{array}$ \\
\hline UO40 & 16 & $10.43 \pm 0.22^{\mathrm{c}}$ & $\begin{array}{c}0.54 \pm \\
0.01^{\mathrm{b}}\end{array}$ \\
\hline UO60 & 6 & $8.85 \pm 0.24^{\mathrm{a}, \mathrm{b}}$ & $\begin{array}{c}0.47 \pm \\
0.00^{\mathrm{a}}\end{array}$ \\
\hline UO80 & 3 & $8.41 \pm 0.09^{\mathrm{a}}$ & $0.47 \pm$ \\
& 12 & $9.267 \pm 0.16^{\mathrm{b}}$ & $0.43 \pm$ \\
\hline VO60 & 336 & $12.03 \pm 0.45^{\mathrm{a}}$ & $0.03^{\mathrm{a}}$ \\
\hline AD & & & $0.56 \pm$ \\
& & & $0.04^{\mathrm{b}}$ \\
\hline
\end{tabular}

Data for moisture content and water activity are reported as means \pm standard deviations of three replicates. Values of the same column with different superscript letters $\left({ }^{a-d}\right)$ are significantly different $(p<0.05)$ according to Duncan's multiple range tests.

UO40/ UO60/ UO80: Universal oven drying at $40^{\circ} \mathrm{C} / 60^{\circ} \mathrm{C} / 80^{\circ} \mathrm{C}$; VO60: Vacuum drying at $60^{\circ} \mathrm{C}$; AD: Air drying in a shaded place $\left(35^{\circ} \mathrm{C}\right)$ with appropriate air flow.

\subsection{Extraction Yield and Total Phenolic Content of $C$. Nutans Leaves}

The influence of different drying condition and extraction techniques on the extraction yield and TPC of $C$. nutans is showed in Fig. 2 and Fig. 3. The overall results showed that the combination of different drying condition and extraction techniques produce significant effect on crude extract and TPC yield ( $\mathrm{p}<0.05$; Fig. 2 and Fig. 3) of $C$. nutans. Dried leaves extracted through soxhlet extraction obtained higher extraction yield that ranges from $10.85 \%$ to $17.18 \%$ as compared to other extraction techniques.

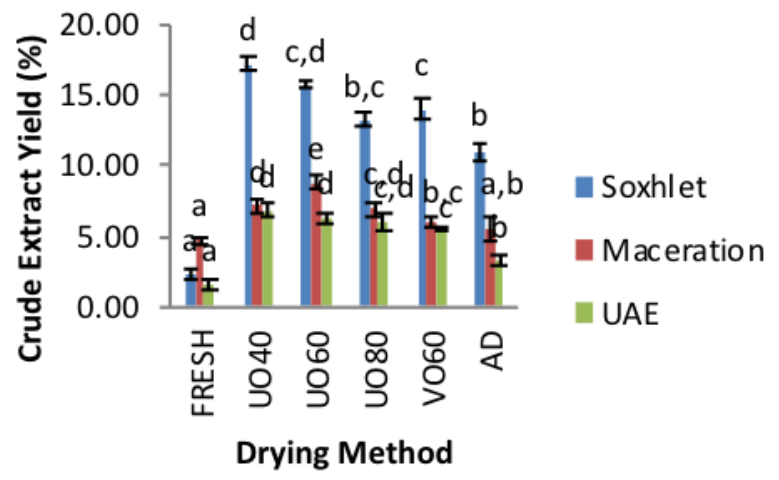

Fig. 2: Impact of different drying methods and extraction techniques on extract yield of $C$. nutans leaves

Data for extract yield are reported as means \pm standard deviations of three replicates. Bars of the same color with different superscript letters $\left({ }^{\mathrm{a}-\mathrm{e}}\right)$ are significantly different $(\mathrm{p}<0.05)$ according to Duncan's multiple range tests.

UO40/ UO60/ UO80: Universal oven drying at $40^{\circ} \mathrm{C} / 60^{\circ} \mathrm{C} / 80^{\circ} \mathrm{C}$; VO60: Vacuum drying at $60^{\circ} \mathrm{C}$; AD: Air drying in a shaded place $\left(35^{\circ} \mathrm{C}\right)$ with appropriate air flow.

The TPC yield from this study ranged from 41.06 to $65.92 \mathrm{mg}$ $\mathrm{GAE} / \mathrm{g}$. Results shows that the application of high temperature $\left(80^{\circ} \mathrm{C}\right)$ for drying significantly damage heat sensitive bioactive compound. Oven dried leaves at $80^{\circ} \mathrm{C}$ obtained the lowest TPC for all extraction techniques ranging from 41.06 to $46.24 \mathrm{mg} \mathrm{GAE} / \mathrm{g}$. Long duration of drying under hot air circulation has also shown to affect the TPC yield of samples as UO40 obtained the second lowest yield after UO80 for all the extraction techniques, ranging from 41.91 to $49.10 \mathrm{mg} \mathrm{GAE} / \mathrm{g}$. This could be due to the degradation of bioactive compounds when subjected to hot air for a longer duration of time which then resulted in lower TPC yield.

The combination of drying $C$. nutans leaves using universal oven at $60^{\circ} \mathrm{C}$ and soxhlet extraction obtained the highest TPC yield at $65.92 \pm 2.19 \mathrm{mg} \mathrm{GAE} / \mathrm{g}$. Fresh C. nutans leaves obtained TPC 
ranging from 46.97 to $63.78 \mathrm{mg} \mathrm{GAE} / \mathrm{g}$ through different extraction techniques. Results from this study showed that high TPC yield can still be retained in the samples when suitable drying condition is applied.

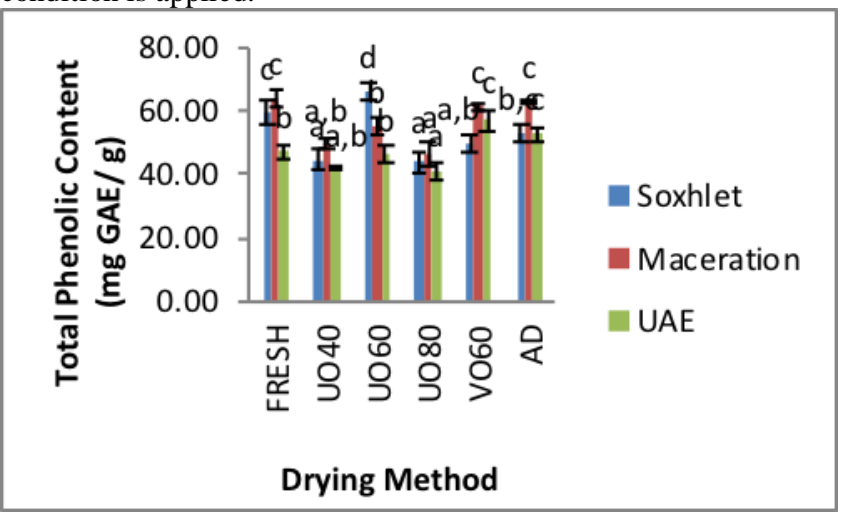

Fig. 3: Impact of different drying methods and extraction techniques on TPC of $C$. nutans leaves

Data for TPC yield are reported as means \pm standard deviations of three replicates. Bars of the same color with different superscript letters $\left({ }^{\mathrm{a}-\mathrm{c}}\right)$ are significantly different $(\mathrm{p}<0.05)$ according to Duncan's multiple range tests.

UO40/ UO60/ UO80: Universal oven drying at $40^{\circ} \mathrm{C} / 60^{\circ} \mathrm{C} / 80^{\circ} \mathrm{C}$; VO60: Vacuum drying at $60^{\circ} \mathrm{C}$; $\mathrm{AD}$ : Air drying in a shaded place $\left(35^{\circ} \mathrm{C}\right)$ with appropriate air flow.

\section{Conclusion}

The results showed that physical properties and TPC of $C$. nutans leaves were affected by different drying condition and extraction technique. The combination of drying $C$. nutans leaves using oven at $60^{\circ} \mathrm{C}$ and soxhlet extraction obtained the highest total phenolic content yield at $65.92 \pm 2.19 \mathrm{mg} \mathrm{GAE} / \mathrm{g}$

\section{Acknowledgement}

The authors would like to express their gratitude to Sabah Economic Development and Investment Authority (SEDIA) and Universiti Malaysia Sabah (UMS) for their unwavering support and assistance in this research project. Also, special thanks to Ministry of Higher Education for providing financial support via MyBrain15 scholarship.

\section{References}

[1] Alam, A., Ferdosh, S., Ghafoor, K., Hakim, A., Juraimi, A. S., Khatib, A., \& Sarker, Z. I. (2016). Clinacanthus nutans: A review of the medicinal uses, pharmacology and phytochemistry. Asian Pacific Journal of Tropical Medicine, 9(4), 402-409.

[2] Arullappan, S., Rajamanickam, P., Thevar, N. \& Kodimani, C.C. (2014). In Vitro Screening of Cytotoxic, Antimicrobial and Antioxidant Activities of Clinacanthus nutans (Acanthaceae) leaf extracts. Tropical Journal of Pharmaceutical Research, 13(9), 1455-1461.

[3] Aslam, M. S., Ahmad, M. S., \& Mamat, A. S. (2015). Clinacanthus nutans extracts are antioxidant with antiproliferative effect on cultured human cancer cell lines. Evidence-based complementary and alternative medicine. International Journal of Pharmacy and Pharmaceutical Sciences, 7(2), 30-33.

[4] Blainski, A., Lopes, G. C., \& De Mello, J. C. P. (2013). Application and analysis of the Folin Ciocalteu method for the determination of the total phenolic content from Limonium Brasiliense L. Molecules, 18(6), 6852-6865.

[5] Dai, J., \& Mumper, R. J. (2010). Plant phenolics: extraction, analysis and their antioxidant and anticancer properties. Molecules, 15(10), 7313-7352.

[6] Freeman, B. C., \& Beattie, G. A. (2008). An overview of plant defenses against pathogens and herbivores. The Plant Health Instructor. DOI: 10.1094/PHI-I-2008-0226-01.

[7] Ho, S. Y., Tiew, W. P., Priya, M., Mohamed, S. A. S., \& Gabriel, A A. (2013). Phytochemical analysis and antibacterial activity of methanolic extract of Clinacanthus nutans leaf. International Journal of Drug Development and Research, 5(3), 349-355.

[8] Huang, D., Guo, W., Gao, J., Chen, J. \& Olatunji, J. O. (2015). Clinacanthus nutans (Burm. f.) Lindau Ethanol Extract Inhibits Hepatoma in Mice through Upregulation of the Immune Response, Journal of Molecules. 20(9), 17405-17428.

[9] Khoo, L. W., Mediani, A., Zolkeflee, N. K. Z., Leong, S. W., Ismail I. S., Khatib, A., Shaari, K. \& Abas, F. 2015. Phytochemical diversity of Clinacanthus nutans extracts and their bioactivity correlations elucidated by NMR based metabolomics. Phytochemistry Letters. 14,123-133.

[10] Kumar, S. (2013). Efficient Method of Storage of Dry Herbs. Journal for Drugs and Medicines. 5(2), A1-A3.

[11] Kunsorn, P., Ruangrungsi, N., Lipipun, V., Khanboon, A. \& Rungsihirunrat, K. (2013). The identities and anti-herpes simplex virus activity of Clinacanthus nutans and Clinacanthus siamensis. Asian Pacific Journal of Tropical Biomedicine, 3(4): 284-290.

[12] Lusia, B. M., Hasmadi, M., Zaleha, A. \& Mohd Fadzelly, A. (2015) Effect of different drying methods on phytochemicals and antioxidant properties of unfermented and fermented teas from Sabah Snake Grass (Clinacanthus nutans Lind.) leaves. International Food Research Journal. 22(2), 661-670.

[13] Mai, C. W., Yap, K.S. I., Kho, M. T., Ismail, N. H., Yusoff, K., Shaari, K., Chin, S.Y. \& Lim, E. S. H. (2016). Mechanisms Underlying the Anti-Inflammatory Effects of Clinacanthus nutans Lindau Extracts: Inhibition of Cytokine Production and Toll-Like Receptor-4 Activation. Frontiers in Pharmacology. 7,7.

[14] Pannangpetch, P. Laupattarakasem, P., Kukongviriyapan, V., Kukongviriyapan, U., Kongyingyoes, B. \& Aromdee, C. (2007). Antioxidant activity and protective effect against oxidative hemolysis of Clinacanthus nutans (Burm.f) Lindau. Songklanakarin Journal of Science and Technology. 29(1), 1-9.

[15] Peng, T. W., Wen, P. X., Han, C. J. \& Akowuah, G. A. (2015). Effect of methanol extract of Clinacanthus nutans on serum biochemical parameters in rats. Journal of Molecules. 20,10822-10838

[16] Pham, H. N. G. Van, Nguyen, V. T., Vuong, Q. V., Bowyer, M. C. \& Scarlett, C. J. (2015). Effect of extraction solvents and drying methods on the physicochemical and antioxidant properties of Helicteres hirsuta Lour. Leaves. Journal of Technologies. 3,285301

[17] Puranik, V., Chauhan, D. K., Mishra, V., \& Rai, G. K. (2012). Effect of drying techniques on the physicochemical and bioactive components of selected medicinal herbs. Ann Phytomed, 1, 23-29.

[18] Raya, K. B., Ahmad, S. H., Farhana, S. F., Mohammad, M., Tajidin, N. E., \& Parvez, A. (2015). Changes in phytochemical contents in different parts of Clinacanthus nutans (Burm. f.) lindau due to storage duration. Bragantia, 74(4), 445-452.

[19] Sakdarat, S., Shuyprom, A., Pientong , C., Ekalaksananan, T. \& Thongchai, S. (2009). Bioactive constituents from the leaves of Clinacanthus nutans Lindau. Bioorganic \& Medicinal Chemistry. 17:1857-1860.

[20] Solibun, A., \& Sivakumar, K. (2016). Sabah snake grass extract pre-processing: Preliminary studies in drying and fermentation. In IOP Conference Series: Earth and Environmental Science (Vol. 36, No. 1, p. 012066). IOP Publishing.

[21] Susantikarn, P., \& Donlao, N. (2016). Optimization of green tea extracts spray drying as affected by temperature and maltodextrin content. Int. Food Res. J, 23, 1327-1331.

[22] Thawaranantha, D., Balachandra, K., Jongtrakulsiri, S., Chavalittumrong, P., Bhumiswasdi, J. \& Jayavasu, C. (1992). In vitro antiviral activity of Clinacanthus nutans on varicella zoster virus. Siriraj Hospital gazette. 44:285-291.

[23] Tu, S. F., Liu, R. H., Cheng, Y. B., Hsu, Y. M., Du, Y. C., ElShazly, M., ... \& Chang, F. R. (2014). Chemical constituents and bioactivities of Clinacanthus nutans aerial parts. Molecules, 19(12), 20382-20390.

[24] Wang, L., \& Weller, C. L. (2006). Recent advances in extraction of nutraceuticals from plants. Trends in Food Science \& Technology, 17(6), 300-312.

[25] Zulkipli, I. N., Rajabalaya, R., Idris, A., Sulaiman, N. A., \& David, S. R. (2017). Clinacanthus nutans: a review on ethnomedicinal uses, chemical constituents and pharmacological properties. Pharmaceutical biology, 55(1), 1093-1113. 